\title{
Trade-offs in traffic: does being mainly a car driver or a cyclist affect adaptive behaviour while driving and cycling?
}

\author{
Sara Nygårdhs ${ }^{1,2^{*}}$ (D, Katja Kircher ${ }^{1}$ (i) and Björn J. E. Johansson² (B)
}

\begin{abstract}
Aim: Road users, such as cyclists and car drivers, are constantly adapting to each other and to the road infrastructure. This study aimed to investigate what trade-offs can be observed when drivers and cyclists adapt to other road users and to the infrastructure.

Methods: A semi-controlled study was carried out in an urban traffic environment, where all participants travelled the same route twice, once as a cyclist and once as a car driver. The extended control model was used as an analytical framework to examine how people adapt depending on their main and current road-user role, experiencing different infrastructure and complexity.

Results: The results revealed possible trade-offs made while adapting, mainly in relation to rule-following. No differences in adaptive behaviour between people who mostly drive and people who mostly cycle were found. The current situational demands influence both the need to adapt and the adaptation carried out. A more complex traffic environment led to increased information intake, measured by glance behaviour.
\end{abstract}

Keywords: Behavioural adaptation, Cyclist, Driver, ECOM, Comfort zone, Complexity

\section{Introduction}

Travelling from one point to another typically has several, partly conflicting, goals. There are goals of getting to the destination, travelling safely, not using too much effort, time efficiency, comfort and more. To meet these goals, road users constantly adapt to each other and to the traffic environment. Adaptation is a prerequisite for making it possible for multiple road users to safely move about concurrently in the traffic environment.

Although road-user adaptation in traffic has been studied before, for example in evaluating the effects of road-safety measures (e.g. [1, 2]), to the best of our knowledge, adaptations made by the same individual but in different road-user roles in real traffic have not been investigated. Knowledge about differing adaptations in the same situations due to road-user role can lead to

\footnotetext{
* Correspondence: sara.nygardhs@vti.se

1'Swedish National Road and Transport Research Institute (VTI), 58195 Linköping, Sweden

${ }^{2}$ Department of Computer and Information Science, Linköping University, 58183 Linköping, Sweden
}

\subsection{Aim}

The aim of this paper is to investigate what observable trade-offs are made when adapting to other road users and the infrastructure, as a cyclist and as a car driver in the same traffic environment, taking the main role of the road user into consideration. From now on, the road-user role with which a person is most familiar will be called the character role. The hypothesis is that the character role (as a driver or cyclist) will affect how the adaptation is carried out.

The extended control model (ECOM) [3, 4] is applied to analyse whether road users behave differently in similar situations, depending on their character role, their current road-user role and the complexity of the environment. In the next section, an overview of ECOM is 
given, together with its implications for theories on adaptive behaviour.

\subsection{Adaptation in ECOM}

While transporting themselves as road users, people make proactive, top-down adaptations based on their own preferences and expectations, but also reactive, bottom-up adaptations to the current and specific situation. These adaptations are not independent but constantly influence each other, since adapting to a situation also means influencing it, which in turn leads to a new, updated situation within which new adaptations can be made. The extended control model (ECOM) acknowledges that top-down and bottomup processing can occur simultaneously, and that the pursuit of goals goes on in different control layers simultaneously [4]. Figure 1 shows a visualisation of the model, where goals and intentions are described in several layers, or time-frames, concurrently [4]. While the goals of a journey are planned in the targeting layer, the overall location and the status of the vehicle are handled in the monitoring layer. The position relative to other vehicles is taken care of in the regulating layer, while continuous control, with reactive adaptations to maintain an intended speed and a safe distance from other vehicles, is carried out in the tracking layer. The activities of the tracking layer are carried out momentarily and automatically, which means that mental resources can be allocated to another layer. ${ }^{1}$

The same situation can be handled differently in terms of when, where and how the adaptation takes place. Consider a driver approaching a signalised intersection with the intention to turn right, when there is a cyclist on a parallel cycle path going straight on. The driver can acknowledge the cyclist ahead early on, adapting to him or her by releasing the gas pedal to let the cyclist pass at the green signal, without ever overtaking the cyclist. Another option is to overtake, but then brake at the signal and wait for the cyclist to pass. A more reactive adaptation occurs when the driver steps on the brake at the last second after having started to turn right. Finally, by turning into the path of the cyclist, the driver can force the cyclist to adapt.

\subsection{The field of safe travel and comfort zone}

With respect to car driving, Gibson and Crooks [5] introduced the concept "field of safe travel", which is a dynamic field that follows the driver and is affected by surrounding obstacles, both fixed and moving, and by symbols such as signals and road markings. It "exists objectively as the actual field within which the car can safely operate, whether or not the driver is aware of it" [5].

\footnotetext{
${ }^{1}$ In the following, the term "loop" is used when referring to the continuous perceptual cycle within a layer, whereas "layer" refers to the model as such.
}

The field of safe travel has been supplemented with other fields, or zones, in subsequent traffic research. One field that is often used is the comfort zone, within which the road user experiences a feeling of comfort [69]. When in their comfort zone, the road user perceives control over the situation, meaning that there is a feeling of sufficient time and spatial margins around him or her [10]. If a margin, i.e. the boundary of the comfort zone, is exceeded, the feeling of control and comfort is lost, and the road user will adapt to the situation by taking corrective actions. No adaptive behaviours will occur, however, while the road user is within their comfort zone, i.e. when performance is experienced as good enough $[7,10]$.

\subsection{Defining adaptation}

There are many terms for describing adaptation, including compensatory behaviour (see e.g. [11-13]), adaptive behaviour (e.g. [14, 15]), behavioural adaptation (e.g. [16]) and self-regulation (e.g. [17, 18]).

Adaptation can be viewed as a trade-off, i.e. that you gain something by losing something else. This is also acknowledged in ECOM, where one goal can be temporarily suspended to the advantage of another [3]. This trade-off can be between such aspects as rule-following and personal efficiency. An example could be cyclists not stopping at a stop sign if there is no traffic on the intersection. Trade-offs also occur at the cognitive level, where, for example, monitoring can be temporarily suspended to enable enhanced tracking in difficult situations.

Throughout this paper, adaptation is defined as setting the boundary of the comfort zone, in which the demands of the task can be handled comfortably with subjectively experienced control. Adaptive behaviour is displayed in the amendments made to maintain this boundary. Here, individual road-user adaptations to other road users and the infrastructure will be examined using ECOM.

According to ECOM, loss of control occurs when a goal in the targeting, monitoring or regulating layer cannot be fulfilled, or when inappropriate goals and criteria are chosen [4]. Defining adaptation as previously, loss of control indicates that the boundary of the comfort zone has been violated and, hence, that the feeling of comfort has been lost. This feeling of comfort, i.e. the subjectively experienced control, is in turn influenced by expectations of such aspects as efficiency and effort. These expectations are related to character role and current road-user role, which will be further analysed in the following sections.

Hypotheses about observable adaptive behaviours, derived from applying ECOM to adaptation in traffic, are presented in bold italics in the following sections. The relation between ECOM, adaptation predictions and hypothesised observable adaptive behaviour is also given. 


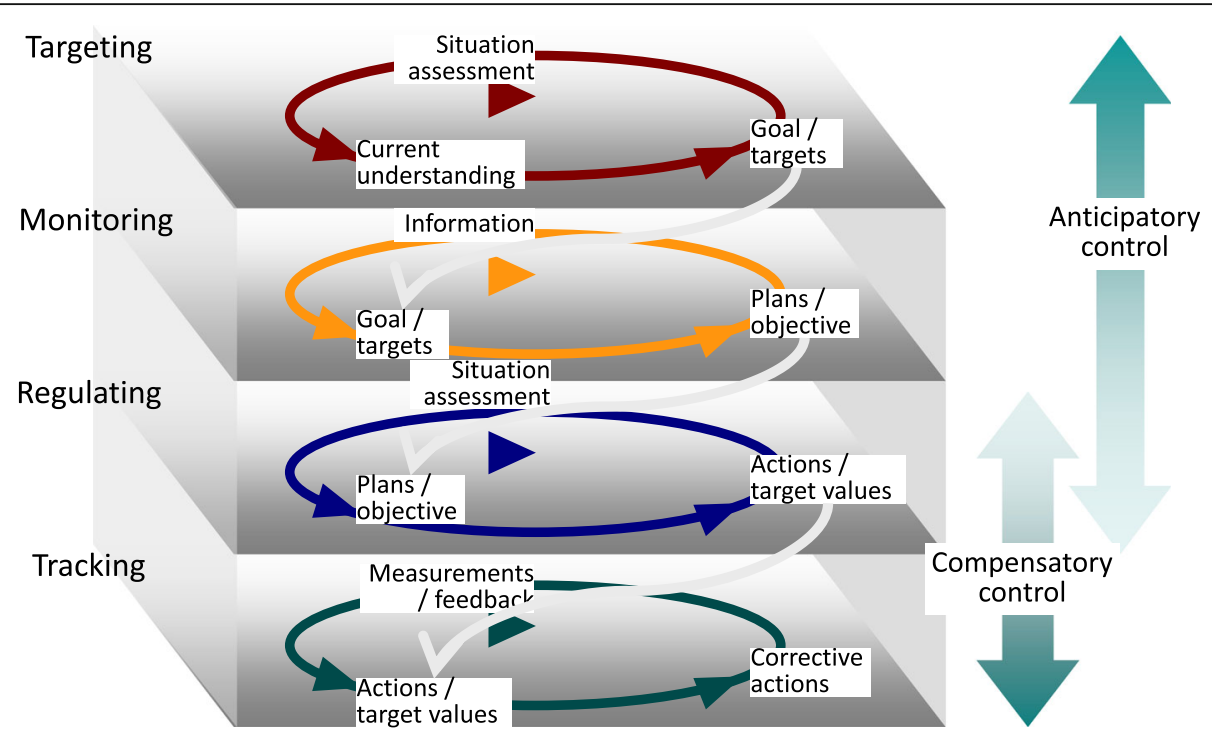

Fig. 1 The extended control model. Retrieved from http://erikhollnagel.com/ideas/ecom.html Copyright 2016 by Erik Hollnagel. Reproduced with permission

\subsection{Character role}

The "character role" of a road user, i.e. the role with which a person is most familiar, is a factor that can influence expectations about infrastructure, other road users and behaviour. Interview and survey studies have shown that character cyclists do not expect other road users, including cyclists, to behave in accordance with the rules $[19,20]$, while character drivers expect that other car drivers will comply to a higher degree than cyclists. We hypothesise that character cyclists will neglect to stop at a stop-rule intersection to a larger degree than character drivers when cycling, and that there will be no difference with respect to stopping behaviour between the character roles when driving. Since rule obedience can be regarded as a strategic decision, these hypotheses belong to the targeting layer of ECOM. Accident studies revealing that cyclists with a driving licence were involved in accidents where drivers should yield to a greater extent than cyclists without a driving licence [21] also point in the direction that not only the present road-user role but also the character role affects expectations. Car drivers turning right and hitting cyclists going straight ahead on a parallel cycle path is a problem at both signalised and unsignalised intersections [21, 22]. It is reasonable to believe that cyclists, as well as other vulnerable road users (VRUs), experience the situation of a rightturning car into their path as more dangerous than the driver inside the car. Given that character cyclists ride their bicycles frequently, they are more likely to come across these situations, and hence will incorporate them into their expectations, to handle the situation with subjectively experienced control. Considering this, and the fact that character drivers seem to expect car drivers to follow the rules, while character cyclists do not, we expect that when cycling, character cyclists will attend more to other vehicles than character drivers will, in situations when other vehicles should yield. If there is a carry-over effect, then character cyclists will also use their experiences as a cyclist when driving a car to acknowledge cyclists. We hypothesise that when turning right at a signalised intersection as a car driver, character cyclists will look for potential cyclists approaching from behind, and yield to them to a greater degree than character drivers will. These hypotheses are examples of adaptations in the regulating loop of ECOM.

Due to the assumed greater experience of character cyclists of cycling through intersections, and that they are expected to neglect the stopping rule more often than character drivers, we also expect them to be more proactive. Hence, we hypothesise that when approaching an intersection with a stop rule, character cyclists will stop pedalling earlier compared to character drivers. This is also carried out in the regulating loop of ECOM.

Overall, more adaptive behaviours are expected to be exhibited by people acting outside of their character role, because of their lesser experience of the current role. Within the tracking layer of ECOM, we hypothesise that in situations of high complexity (see section 1.7), road users who are acting outside their character role will increase their information intake more, compared to when they are acting inside their character role.

\subsection{Current road-user role}

Although cyclists are not perceived as being as predictable and rule-following as car drivers [20, 23], this could 
be a consequence not only of the fact that cycling allows more flexibility than driving, but also that the traffic system is mainly built for cars, which can make it difficult to balance the goals of being law-abiding and efficient and feeling safe at the same time [24, 25]. While the construction of the infrastructure allows cars to go straight ahead in a continuous lane to get to their destination, bicycles on a separated cycle path may have to cross the car lanes or make a detour to get to the same location. Different situational demands are expected to lead to different feelings of comfort, whereas the same situational demands are not expected to alter the feeling of comfort. We therefore suggest that $a$ car driver and a cyclist in a similar traffic situation will not differ with respect to checking for other road users, while a car driver does not check for other road users as much as a cyclist does, if the situational demands for the car driver are lower than for the cyclist. These actions are handled in the monitoring loop of ECOM.

\subsection{Complexity level}

Although previous experience, character role and current road-user role influence how people make proactive adaptations to handle the demands of a task with subjectively experienced control, the current traffic situation must be handled by reactive adaptations. Proactive behaviour, such as setting a speed, influences the complexity of the situation, but so do infrastructural demands and the presence and actions of other road users. The tracking loop of ECOM handles adaptations that are made instantly without conscious attention, such as quick glances. Studies have shown that less visual attention is assigned to objects not directly relevant to the driving task when complexity is higher [26, 27]. We expect that higher complexity in the current situation leads to more frequent gaze changes, longer maximum times between looking at default targets, and fewer glances at objects that are irrelevant to driving and riding performance. For character cyclists, this is expected to be more pronounced when driving, and for character drivers when cycling, as stated previously.

Summing up, it should be possible to find examples of observable adaptive behaviour in relation to character role, current road-user role and complexity level in a real-world field study with character drivers and character cyclists. For the examples here, the targeting, monitoring, regulating and tracking layers of ECOM are represented. Table 1 shows a summary of the factors investigated in the study, the adaptation predictions associated with these and the corresponding layer of ECOM where hypotheses are posted as examples of observable behaviour.

\section{Method}

\subsection{Design}

The research design was a semi-controlled study [28] with a mixed design. Possible candidates for participation were asked to rate how often they drove a car and cycled, respectively, to assess the core of the participants' perceptions of themselves. Individuals who could be categorised as either a character driver or a character cyclist were recruited (Table 2). Each participant both

Table 1 Factors investigated in the study, together with adaptation predictions and the corresponding layer in ECOM

\begin{tabular}{ll}
\hline Factor & Adaptation prediction \\
\hline Character role & Character cyclists in their own role stay within \\
& their comfort zone even when they negotiate \\
& rule-following.
\end{tabular}
Layer of ECOM: Hypothesis as example of observable adaptive behaviour Targeting: When cycling at a stop-rule intersection, character cyclists will neglect to stop to a larger degree than character drivers. When driving at a stop-rule intersection, there will be no difference in stopping behaviour between character cyclists and character drivers.

Character cyclists will try to stay within their comfort zone in their role as drivers as well as cyclists, by controlling the boundaries of the zone more often than character drivers.
Road users who experience high complexity will increase their information intake, and even more so when outside of their character role.

Current road-user role The same situational demands will lead to the same levels of comfort, whereas different situational demands for drivers and cyclists will lead to different levels of comfort.

Complexity level
Road users who experience high complexity will increase their information intake to stay within their comfort zone.
Regulating: When approaching an intersection with a stop rule, character cyclists will stop pedalling earlier compared to character drivers.

When cycling, character cyclists will pay more attention to other vehicles in situations when other vehicles should yield, compared to

character drivers.

When turning right at a signalised intersection as a car driver, character cyclists will a) look for potential cyclists approaching from behind, and b) yield to them to a larger degree than character drivers will.

Tracking: The outcomes in relation to complexity level will be more pronounced for character cyclists when driving, and for character drivers when cycling.

Monitoring: A car driver and a cyclist in a similar traffic situation (going forward at an unsignalised mixed-traffic intersection) will not differ with respect to checking for other road users.

A car driver does not check for other road users as much as a cyclist does if the situational demands for the car driver are lower than for the cyclist (going forward at an unsignalised intersection with separated paths).

Tracking: Higher complexity leads to a) more frequent gaze changes, b) longer maximum times between looking at default targets, and c) fewer glances at objects not relevant to driving and riding performance. 
drove a car and cycled along a specified route in an urban environment with real traffic. The driving route was the same as the cycling route but extended at the end. The only instruction was to behave as they would have done if they had not been in a study. Advantages of the semi-controlled approach include that adaptive behaviour can be studied, while a disadvantage is less control over the situation.

The participants were equipped with a head-mounted eye-tracking system and drove and rode in the city of Linköping, Sweden, while data about glance behaviour, speed and acceleration, together with video recordings, were collected.

The regional ethical committee in Linköping approved the study (Dnr 2017/107-31).

\subsection{Participants}

All interested persons were required to fill in a webbased recruitment form to see if they matched the inclusion criteria. Inclusion criteria were that the participant had a driving licence, at least occasionally used a bicycle for transportation purposes, could bring their bicycle for the study, and fitted into one of the participant groups. Additionally, because of the eye-tracking equipment used, participants whose eyesight could not be corrected to within \pm 4 dioptres were excluded. Because of possible bias problems, no professional drivers were recruited.

In total, 23 participants were recruited (12 women), with an average age of $39 \pm 14$ years. The participant groups consisted of 12 character drivers and 11 character cyclists. The participants were reimbursed with 1000 SEK (appr. 100 Euro) for completing both driving and riding in the study.

\subsection{Procedure}

Each participant was contacted to schedule a time for the cycling and driving, respectively, and was also emailed detailed information about the study. When they arrived at the meeting point in the city, this information was repeated both visually and orally, stressing that the participant should behave as normal, i.e. as though not part of a study. Thereafter, the participant was asked to sign an informed consent form.

\subsubsection{Cycling condition}

Each participant cycled along an approximately $5 \mathrm{~km}$ stretch of road in Linköping, consisting of different types of infrastructure, including both cycle paths and mixed traffic. An experiment leader with a bicycle equipped with a camera facing forward followed each cyclist along the route to film what was happening around the cyclist. At three specific positions along the way, the cyclist stopped, and the experiment leader asked whether anything special had happened during the last segment and gave further guidance instructions for the next road segment.

\subsubsection{Driving condition}

All participants also drove an instrumented car with an experiment leader in the back seat along the same route as for cycling but extended to about $12 \mathrm{~km}$ to include turning right at a large signalised intersection. The traffic lights at the intersection turn green both for cars on the road going straight on and turning right, and for cyclists crossing the road from a cycle path parallel to the road. To ensure that there would be a cyclist to attend to, unknown to the driver, a confederate cyclist was travelling parallel with the driver on the approach to this intersection and aimed to go straight ahead when the driver would be turning right. The confederate cyclist should behave like an ordinary cyclist, which means that no unnecessary risks were taken. Apart from this intervention, the same procedure as for the cycling condition was carried out, whereby the experiment leader gave

Table 2 Grouping criteria from answers on the recruitment form

\begin{tabular}{|c|c|c|}
\hline Character role in study & $\begin{array}{l}\text { answer to "how often do you } \\
\text { drive a car?" }\end{array}$ & $\begin{array}{l}\text { answer to "how often do you } \\
\text { cycle?" }\end{array}$ \\
\hline character driver & $\begin{array}{l}\text { very often } \\
\text { often } \\
\text { sometimes } \\
\text { seldom } \\
\text { never }\end{array}$ & $\begin{array}{l}\text { very often } \\
\text { eften } \\
\text { sometimes } \\
\text { seldom } \\
\text { never }\end{array}$ \\
\hline character cyclist & $\begin{array}{l}\text { very often } \\
\text { eften } \\
\text { sometimes } \\
\text { seldom } \\
\text { never }\end{array}$ & $\begin{array}{l}\text { very often } \\
\text { often } \\
\text { sometimes } \\
\text { seldom } \\
\text { never }\end{array}$ \\
\hline
\end{tabular}

Strikethrough indicates alternatives disqualifying for that role 
guidance instructions at specific positions when the driver stopped.

\subsection{Equipment}

In both the cycling and driving condition, a headmounted eye-tracking system (SMI 2.0, SensoMotoric Instruments, Teltow, Germany) was used.

The participant used his or her own bicycle for the cycling part of the study. The bicycle was equipped with two cameras, one facing forward and one facing the participant. The bicycle used by the following experimenter was equipped with a forward-facing camera. All cameras used in the cycling condition were Garmin Virb (Garmin, Olathe, Kansas, USA).

A Volvo V60 (2013) with automatic transmission was used in the driving condition. The car was equipped with sensors registering the position and speed of both the car itself and the surrounding traffic. Cameras recorded the forward view, the view to the right of the car, the driver and behind the car. All data was registered in a VBox (Racelogic, Buckingham, UK) inside the vehicle.

\subsection{Intersections}

Several intersections were analysed in the study. Table 3 shows photos of the intersections that were subject to analysis, together with further descriptions.

\subsection{Analysis}

The data was annotated in the Observer XT 14.1 (Noldus Information Technology, Wageningen, the Netherlands) software. This was done by manually marking gaze directions, complexity levels etc. in the videos.

Complexity was categorised continuously based on how long it was possible to close one's eyes [30]. The scale of the complexity level goes from 0 to 3 as follows, where the number within parentheses is the time it was possible to close one's eyes: $0(>3 \mathrm{~s}), 1$ (1-3 s), 2 (<1s), 3 (not possible). The same trained person categorised all the data from the study, in both the cycling and the driving condition. Complexity levels were analysed for the cycling and driving condition on approach to and passing through the intersections in Table 3, although for the signalised intersection only the condition of going straight through, which was the same for the driving and cycling condition, was included. Only complexity levels when moving were included in the analyses.

Pedalling behaviour on approach to the mixed traffic intersection with stop rule (intersection C) was categorised by the position where the cyclist stopped pedalling in relation to the stop sign (see Fig. 2). The categories were chosen with the aim of grouping cyclists into proactive (before parking space, $>25 \mathrm{~m}$ before the stop line), reactive (after pedestrian crossing, 0-6 $\mathrm{m}$ before the stop line) and in-between (before pedestrian crossing, 6-25 $\mathrm{m}$ before the stop line) pedalling behaviour.

McNemar tests were performed when looking for changes in people's behaviours, i.e. when there were two related dichotomous variables. Mann-Whitney tests were used on non-parametric data to compare the distributions of two conditions when these had different entities. Pavement riders were excluded from statistical analyses of the mixed-traffic intersection (C), because their situation is not comparable to the others'. In addition, only data from participants who were undisturbed by traffic in front was used for analyses of pedalling behaviour (intersection $\mathrm{C}$ ) and glances towards the right-hand side road (intersections A and B).

Since there were only a few (31) complexity-level 0 cases coded when moving, compared to levels 1 (133), 2 (117) and 3 (118), complexity level 0 was omitted from further analyses. Three-way mixed analyses of variance were carried out on the complexity data, and followed up by Tukey's post-hoc test, when applicable. For the maximum time of looking at non-default targets, only one value per participant and condition was used, i.e. the overall maximum time for all intersections.

For one participant, eye-tracking data was missing in the driving condition, which means that for the glance analyses in the driving condition, data from this person is not included.

All statistical tests were performed with a significance level set to .05 .

\section{Results}

The results are presented divided into the factors given in Table 1. For each analysis, the intersection from which data is used, corresponding to Table 3, is stated within parentheses. The results regarding complexity level in relation to character role are given in the complexity-level section.

\subsection{Character role \\ 3.1.1 Mixed-traffic intersection with stop rule - cycling (intersection C)}

Three participants used the pavement for riding: one character cyclist and two character drivers. Figure 3 shows the participant actions when riding on the mixed road in connection with crossing the mixed-traffic intersection where a stop rule applies.

There was no significant effect of character role on the outcomes of whether they stopped without putting their foot down, stopped with their foot down, walked with their bike or did not stop at all at the intersection, $U=$ 38.0, $z=-.94, p=.412, r=-.21, n=20$ (11 character cyclists, 9 character drivers).

The position in which the cyclists (without motorised traffic in the same direction) stopped pedalling before the intersection did not differ significantly between character 
Table 3 Intersections analysed in the study. A: Unsignalised intersection with separate paths. B: Unsignalised intersection with mixed traffic. C: Mixed-traffic intersection with stop rule. D: Signalised intersection. E. Unsignalised intersection with separated paths and two lanes. Photos: Google "Streetview", digital images, Google Maps (http://google.com), taken in Linköping, Sweden, between June 2014 and August 2018, viewed on 12 June 2019
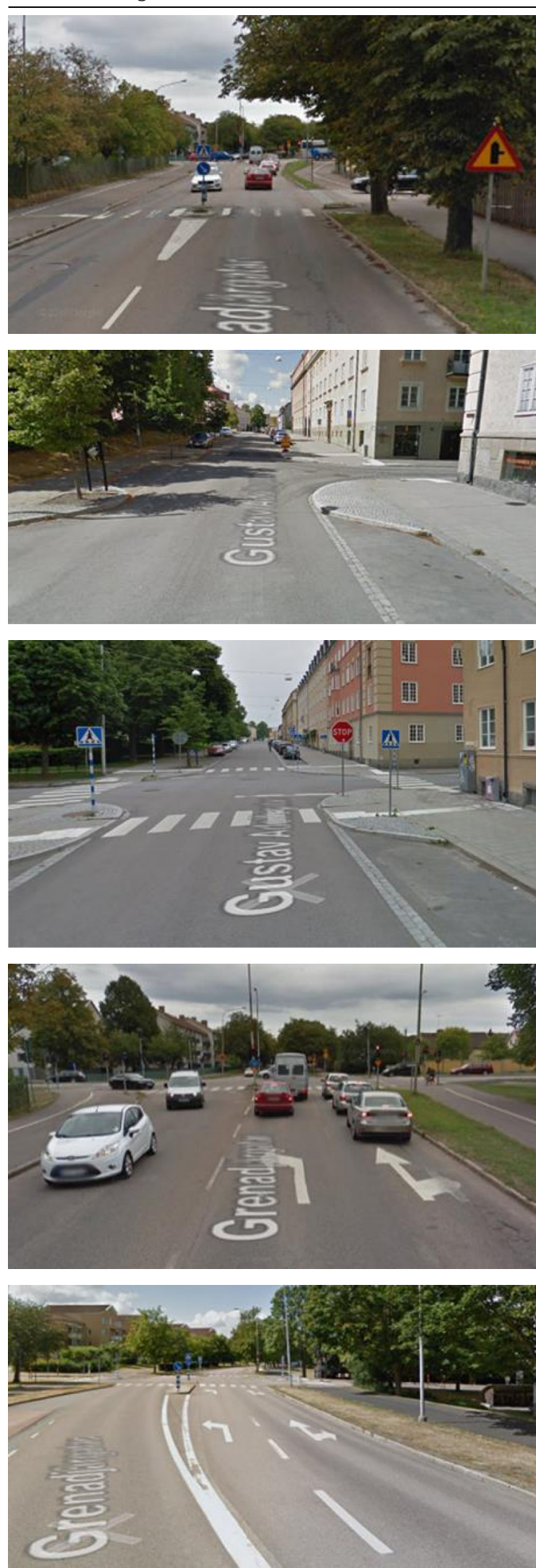

A: Unsignalised intersection with separate paths

- Three-legged intersection.

- Separated paths.

- Road users from the right-hand side road should yield to cars on main road.

- Somewhat unclear rules for cyclists ${ }^{1}$.

Site: Grenadjärgatan/Sparvgatan.

B: Unsignalised intersection with mixed traffic

- Three-legged intersection

- Mixed-traffic road.

- Priority should be given to traffic from the right Site: Gustav Adolfsgatan/Kettilsgatan.

C: Mixed-traffic intersection with stop rule

- Four-legged intersection.

- Mixed traffic road.

- Stop rule.

Site: Gustav Adolfsgatan/Platensgatan.

D: Signalised intersection

- Four-legged intersection.

- Separated paths.

- Traffic signals.

- Drivers turning right should yield to traffic on

the parallel cycle and pedestrian paths.

Site: Grenadjärgatan/Industrigatan.

E: Unsignalised intersection with separate paths and two lanes

- Four-legged intersection.

- Separated paths.

- Road users from the right-hand side road should yield to cars on main road.

- Somewhat unclear rules for cyclists ${ }^{1}$.

Site: Grenadjärgatan/Åbylundsgatan.

${ }^{1}$ The signage can be interpreted such that traffic from the right has to yield to both motorised and cycle traffic on the main road but, according to legislation, it is possible that traffic on the cycle path must yield to traffic from the right [29] 


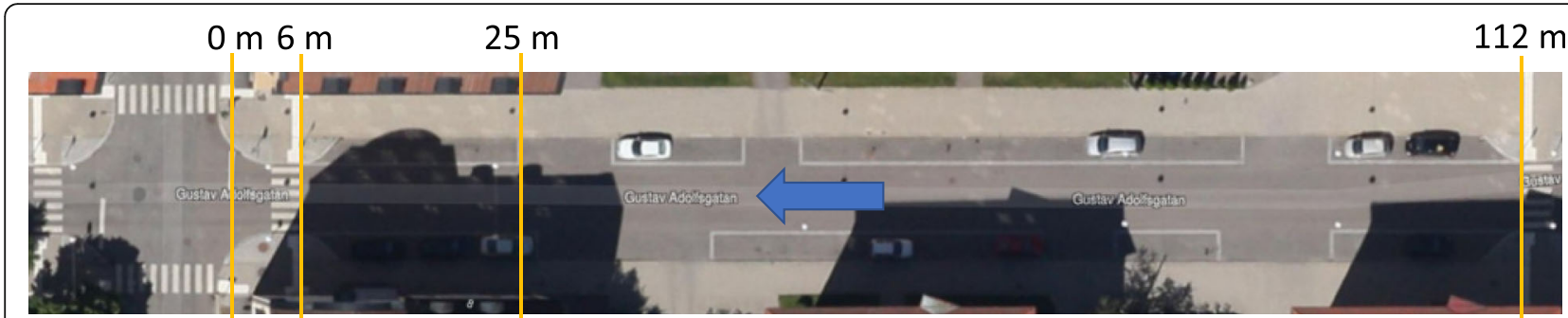

\section{After pedestrian crossing}

Before parking space

\section{Before pedestrian crossing}

Fig. 2 Unsignalised intersection with stop rule in mixed traffic. The vertical lines indicate categorisation of where the participants stopped pedalling in the cycling condition. The blue arrow indicates direction of travel. The distance from the stop line is indicated at the top. Satellite view from hitta.se (https://www.hitta.se/kartan! 58.41699,15.61879,18.57400719715861z/tileLayer!l = 1/tr!! = R2sLM6qm)

cyclists and character drivers, $U=40.00, z=0.58$, $p=.743, r=0.14, n=17$ (9 character cyclists, 8 character drivers).

\subsubsection{Mixed-traffic intersection with stop rule - driving (intersection C)}

Due to the low number of participants in combination with the diverse outcomes in the remainder of this section, data is only reported at a descriptive level without further statistical analysis.
Figure 4 shows the stopping behaviour of the participants when driving a car through the mixed-traffic intersection with stop rule.

\subsubsection{Signalised intersection - cycling (intersection D)}

Figure 5 shows whether the participants, in their current role as cyclists, looked over their shoulder or not before passing the intersection at green signal, depending on the traffic signal on approach to the intersection. Note that, even though there are vehicles to look at over their

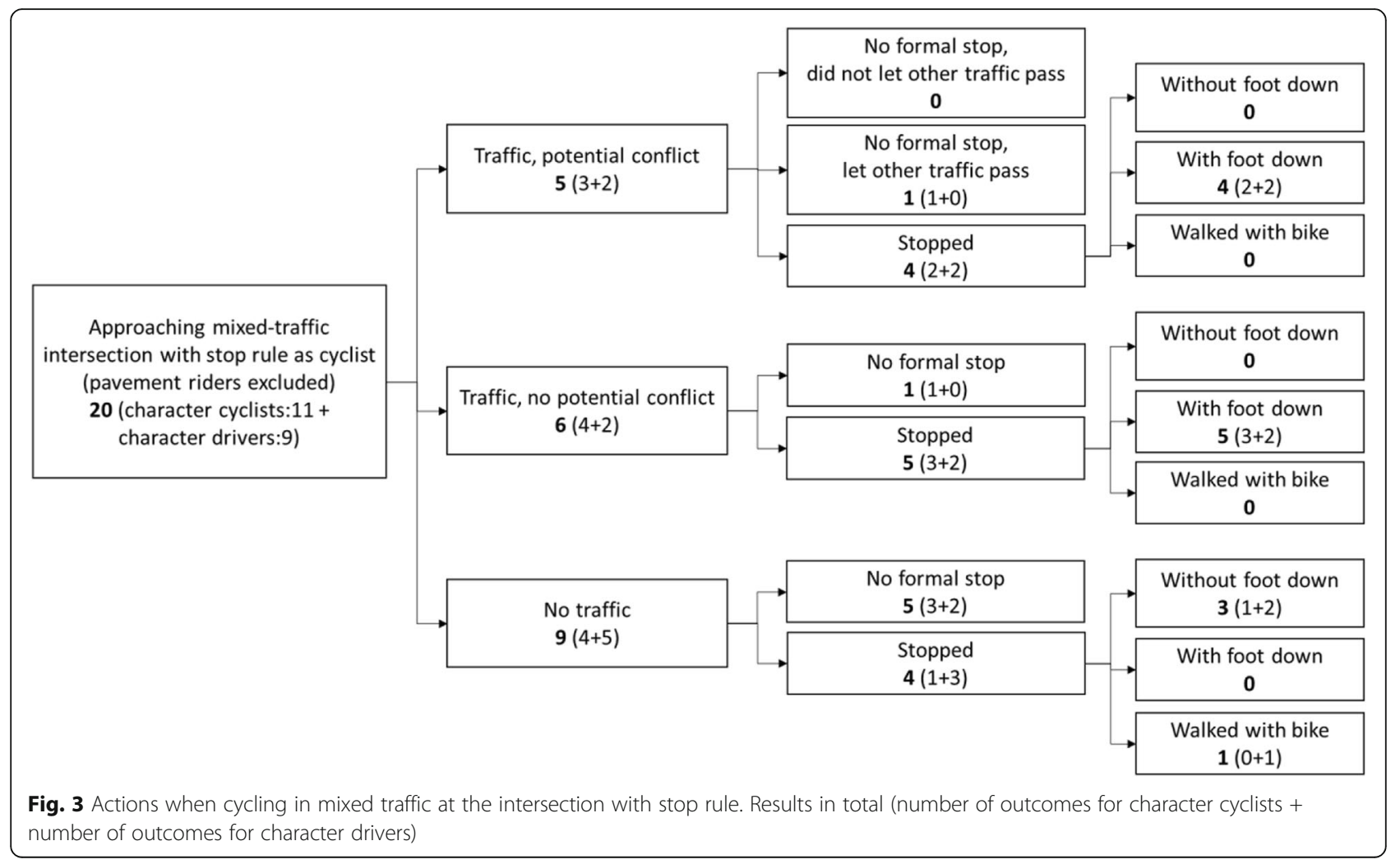




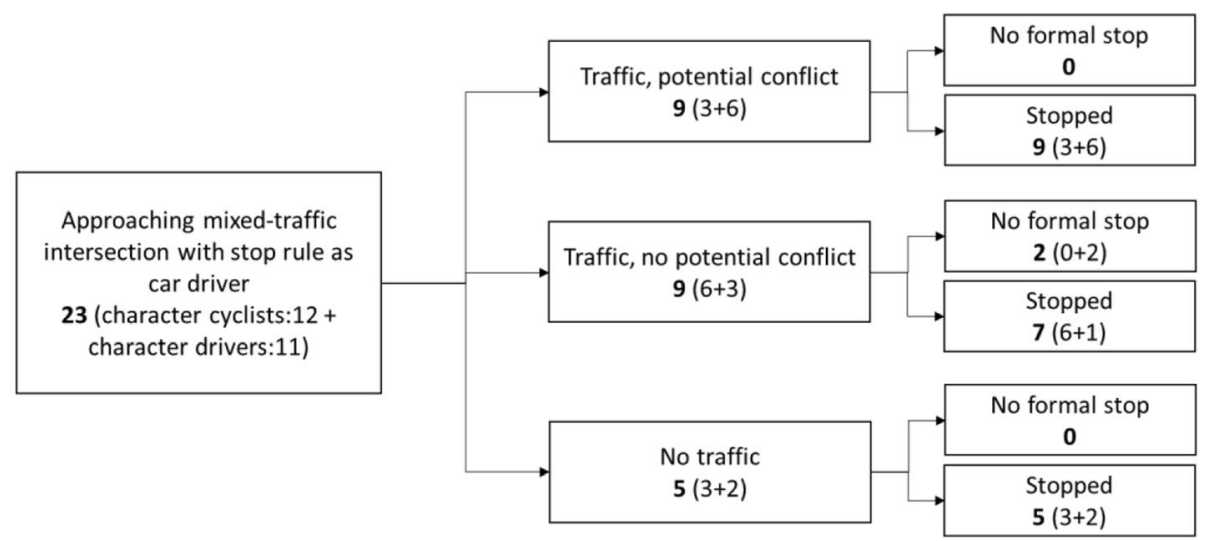

Fig. 4 Stopping behaviour when driving in mixed traffic at the intersection with stop rule. Results in total (number of outcomes for character cyclists + number of outcomes for character drivers)

shoulder, these do not necessarily turn right and cross the cycle path, since they can also continue straight on.

\subsubsection{Signalised intersection - driving (intersection D)}

In their current role as car drivers at the same intersection, see Fig. 6, all participants except one looked for VRUs approaching from behind before turning right. On ten out of 23 occasions, there were road users approaching from behind to attend to and all participants gave way to them.

\subsection{Current road-user role}

3.2.1 Unsignalised intersections with side road to the right (intersections $a$ and $B$ )

Table 4 shows the sample sizes and analyses made regarding the current road-user role.

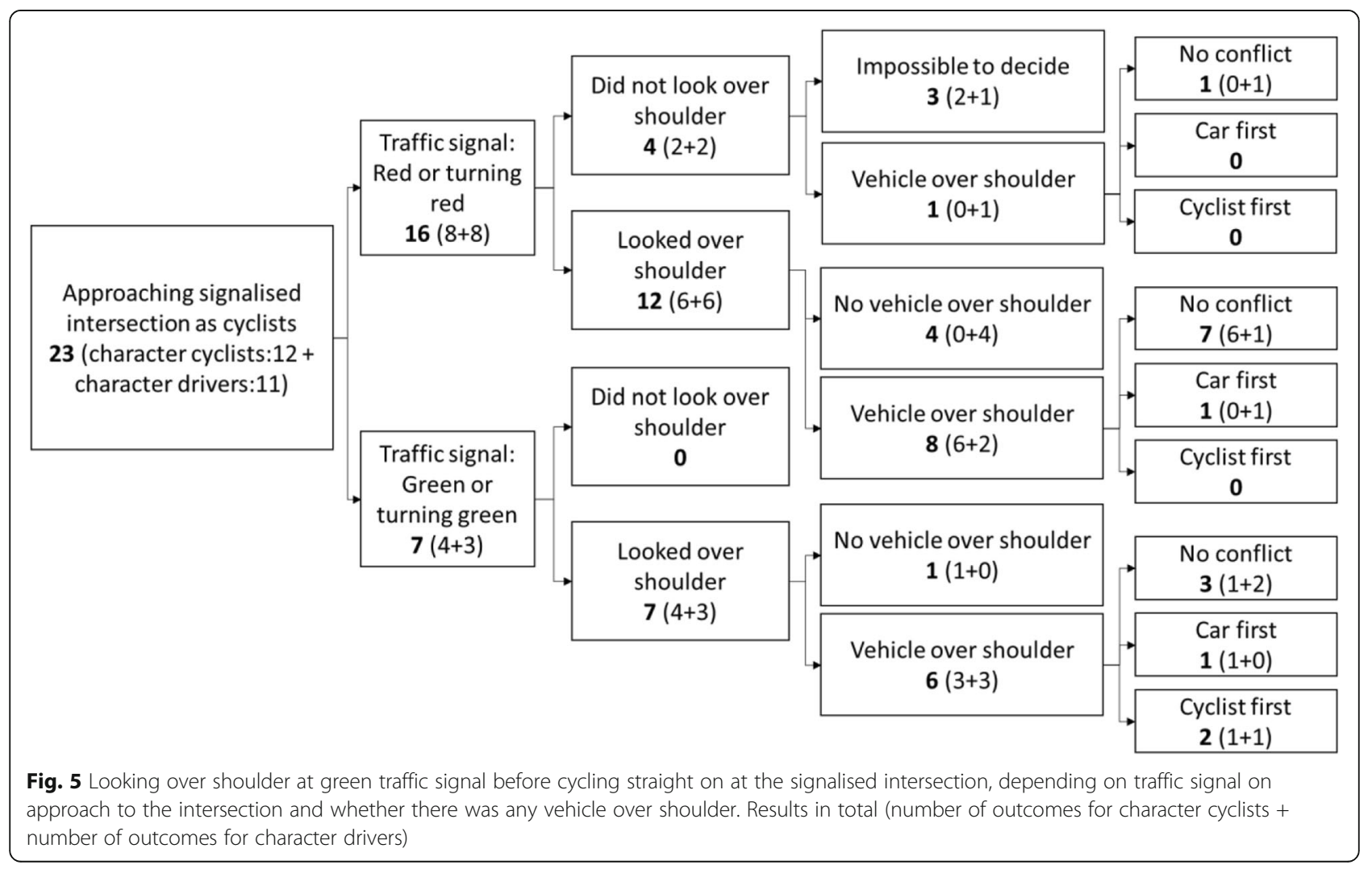




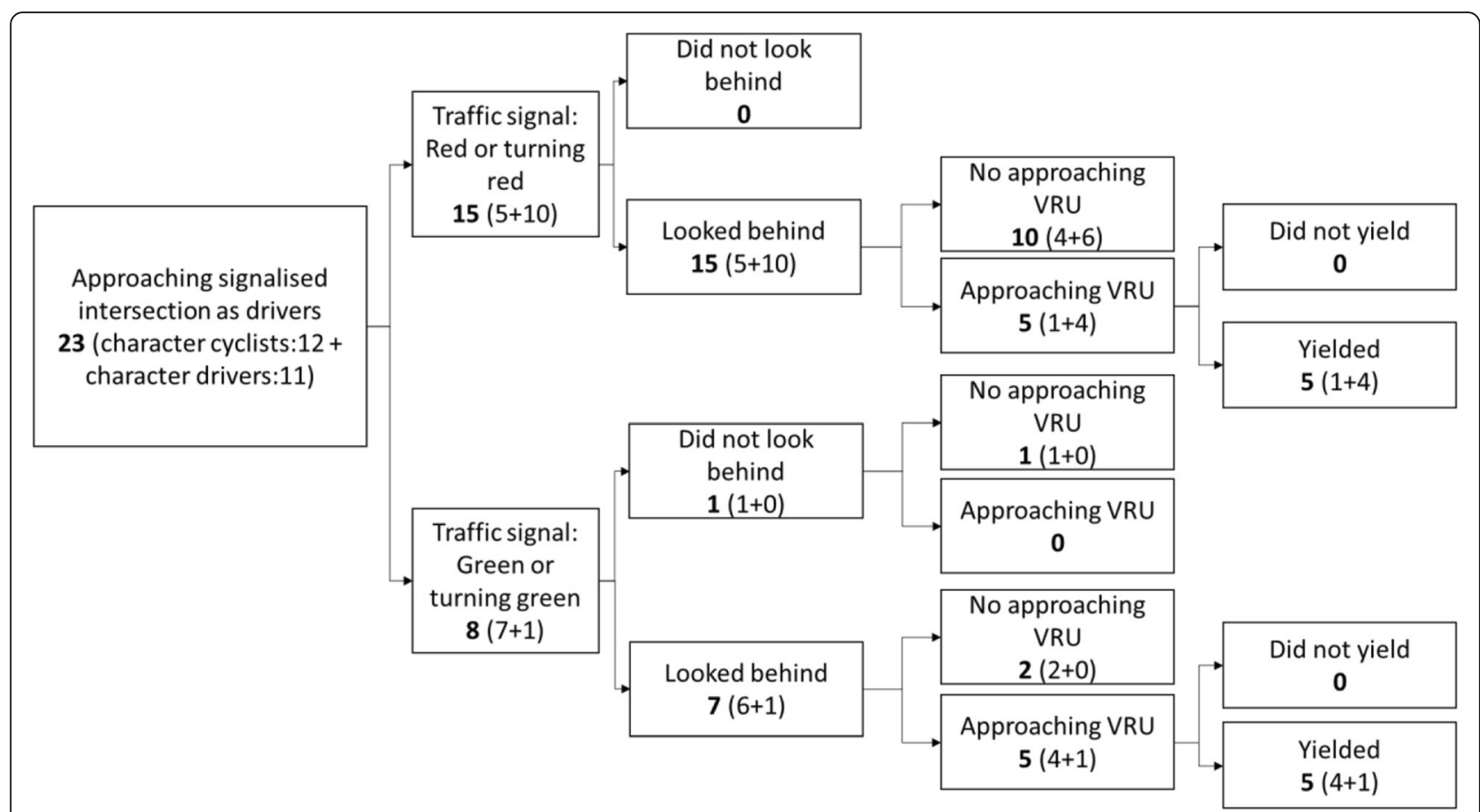

Fig. 6 Looking for VRUs from behind and yielding behaviour when driving and turning right at the signalised intersection, depending on traffic signal on approach to the intersection and whether there was an approaching VRU to yield to. Results in total (number of outcomes for character cyclists + number of outcomes for character drivers)

Table 4 Sample sizes ( $n=$ total, $C C=$ character cyclists, $C D=$ character drivers) and outcomes of McNemar's tests for the current road-user role. Exclusion criteria: disturbed by traffic in front, no eye tracking, pavement riding. Intersections according to Table 3

\begin{tabular}{|c|c|c|c|c|c|c|c|}
\hline \multirow[t]{2}{*}{ Intersection } & \multirow[t]{2}{*}{ Looked to right } & \multirow[t]{2}{*}{$\mathrm{n}$} & \multirow[t]{2}{*}{$\mathrm{n}$} & \multirow[t]{2}{*}{$C D$} & \multicolumn{3}{|c|}{ McNemar's exact test } \\
\hline & & & & & df & test statistic & $p$ \\
\hline \multirow[t]{4}{*}{ A: Separated } & & 19 & 10 & 9 & 1 & 6.1 & .008 \\
\hline & driving and cycling & 9 & 5 & 4 & & & \\
\hline & cycling only & 8 & 4 & 4 & & & \\
\hline & driving only & 0 & 0 & 0 & & & \\
\hline \multirow[t]{4}{*}{ B: Mixed } & & 17 & 9 & 8 & 1 & 0 & 1.000 \\
\hline & driving and cycling & 14 & 6 & 8 & & & \\
\hline & cycling only & 2 & 2 & 0 & & & \\
\hline & driving only & 1 & 1 & 0 & & & \\
\hline \multirow[t]{4}{*}{$A$ and $B$, cycling } & & 17 & 9 & 8 & 1 & 0 & 1.000 \\
\hline & at both intersections & 14 & 7 & 7 & & & \\
\hline & at mixed only & 1 & 0 & 1 & & & \\
\hline & at separated only & 1 & 1 & 0 & & & \\
\hline \multirow[t]{4}{*}{$A$ and $B$, driving } & & 17 & 8 & 9 & 1 & 4.9 & .021 \\
\hline & at both intersections & 6 & 4 & 2 & & & \\
\hline & at mixed only & 9 & 3 & 6 & & & \\
\hline & at separated only & 1 & 0 & 1 & & & \\
\hline
\end{tabular}


At the mixed-traffic intersection, $82 \%$ of the participants looked to their right both when driving and cycling, whereas in total $47 \%$ of the participants looked at the right-hand side road, both when driving and cycling at the unsignalised intersection with separate paths.

There was no significant difference between looking at the right-hand side road at the mixed-traffic intersection in the current role as cyclist or as car driver. One participant only checked the side road on the right as a driver but not as a cyclist, while two people looked to their right when cycling only.

The results showed that, when going forward into an unsignalised intersection with separate paths, there was a significant difference in looking to the right in the current role as cyclist versus as driver. Eight participants looked into the side road on the right as cyclists but not as drivers, while no one looked to the right only as a car driver.

For the cycling condition, no significant difference regarding looking into the right-hand side road between the mixed road and the separated-paths road was shown. In the driving condition, there was a significant difference in that drivers did not look into the right-hand side road on the separated-paths road as much as they did on the mixed-traffic road.

\subsection{Complexity level}

\subsubsection{All intersections going straight on (intersections $A, B$,}

\section{$C, D$ and $E$ )}

The gaze change frequency was significantly higher for complexity level $2(1.06 / \mathrm{s})$ than for the others, and it was higher for complexity level $3(0.91 / \mathrm{s})$ than for complexity level $1(0.51 / \mathrm{s}), F(2,46.92)=61.44, p<.001$. There was no significant interaction effect between complexity level and whether the participant was in their character role or not, $F(2,44.13)=1.42, p=.254$.
There was a main effect of complexity level on the maximum time spent looking at non-default targets $(F$ $(2,69)=14.74, p<.001)$. The maximum time spent looking at non-default targets was longer for complexity level 1 (9.3 s) than for complexity levels 2 (3.8 s) or 3 (4.4 s).

The number of glances at non-relevant objects was significantly lower at complexity level 3 (harmonic mean: $0.17)$ and $2(0.20)$ than at complexity level $1(1.65), F(2$, $46.26)=44.37, p<.001$. There were no significant effects depending on whether the participants were in their character role or not.

\section{Discussion}

The aim of this study was to examine what observable trade-offs are made when adapting to other road users and the infrastructure, when cycling and driving in the same traffic environment, and whether being a character cyclist or a character driver affects adaptation. We did find some observable trade-offs, which are discussed below. The overall outcome of the study in relation to ECOM and the adaptation predictions show that predictions in relation to current road-user role and complexity level were supported, but not those related to character role (Table 5).

The outcomes all point in the same direction: that adaptive behaviour is not governed by character role but by the current road-user role and the current situation. The trade-offs observed in the different ECOM layers support this and can be summarised as being related to the main categories of rule-following (targeting loop of ECOM), safety (targeting), efficiency (regulating) and physical comfort (regulating). The goals of these categories are traded both within and between different layers of ECOM, depending on the situation and personal

Table 5 Overview of outcome of the study in relation to ECOM and the adaptation predictions in Table 1

\begin{tabular}{|c|c|c|}
\hline Factor & Adaptation prediction & Outcome in relation to ECOM \\
\hline \multirow[t]{3}{*}{ Character role } & $\begin{array}{l}\text { Character cyclists in their own role stay within their } \\
\text { comfort zone even when they negotiate } \\
\text { rule-following. }\end{array}$ & \multirow{3}{*}{$\begin{array}{l}\text { The prediction was not supported by the hypotheses in } \\
\text { the targeting, regulating or tracking layers. Rather, the } \\
\text { current road-user role seems to affect rule-following at } \\
\text { the stop sign. }\end{array}$} \\
\hline & $\begin{array}{l}\text { Character cyclists will try to stay within their comfort } \\
\text { zone in their role as drivers as well as cyclists, by } \\
\text { controlling the boundaries of the zone more often } \\
\text { than character drivers. }\end{array}$ & \\
\hline & $\begin{array}{l}\text { Road users who experience high complexity will } \\
\text { increase their information intake, and even more } \\
\text { so when outside of their character role. }\end{array}$ & \\
\hline Current road-user role & $\begin{array}{l}\text { The same situational demands will lead to the same } \\
\text { levels of comfort, whereas different situational } \\
\text { demands for drivers and cyclists will lead to } \\
\text { different levels of comfort. }\end{array}$ & $\begin{array}{l}\text { The prediction was supported by the hypotheses in the } \\
\text { monitoring layer. } \\
\text { This implies that the current road-user role and the } \\
\text { demands for that role affect whether other road users are } \\
\text { checked at an intersection. }\end{array}$ \\
\hline Complexity level & $\begin{array}{l}\text { Road users who experience high complexity will } \\
\text { increase their information intake to stay within their } \\
\text { comfort zone. }\end{array}$ & $\begin{array}{l}\text { The prediction was partly supported by the hypotheses in } \\
\text { the tracking layer. Complexity seems to affect road users' } \\
\text { information intake. }\end{array}$ \\
\hline
\end{tabular}


preference in order to retain the feeling of control and hence stay within their comfort zone.

Trade-offs between rule-following and personal efficiency could be seen for both cyclists and drivers when they did not stop at the stop sign. In contrast, trading personal efficiency for rule-following was observed for cyclists at the stop-rule intersection when they stopped with their foot down even though there was no potential conflict with other traffic. The same was noted for drivers giving way to VRUs before turning right at the signalised intersection, with the important difference that not following the regulations would lead to a conflict. Personal efficiency was also traded for less physical effort by the cyclist transferring into a pedestrian with a bike, whereas the physical effort of controlling a vehicle was traded for rule-following by cyclists who balanced on their bikes at the stop sign.

On the mixed-traffic section, pavement riders were noted, who could be considered to trade rule-following for experienced safety. Although it is not legal, it might feel safer to use the pavement and not interfere with motorised vehicles.

The fact that car drivers checked less frequently for possible traffic from the right on a main road with separated paths than in mixed traffic is probably a result of the different demands imposed by both the infrastructure and the regulations at these intersections. When the same infrastructure and regulations were present when both driving and cycling, there was no difference in checking for traffic between the current road-user roles. When the demands on drivers and cyclists were dissimilar, behaviour differed. The road users appear to do what is demanded of them by the setting and rules that apply to their present role. This implies that the situational demands affect the comfort zone and hence adaptation more than either the character role or the current roaduser role.

We could not see that character cyclists were different from character drivers in trying to stay within their comfort zone in their role as drivers or as cyclists, by checking the boundaries more often. Instead, road users who experience traffic situations rated as highly complex increased their information intake, irrespective of whether they were in their character role or not.

The fact that some cyclists did not look over their shoulder before passing the signalised intersection after having waited at a red light could be due to at least two things. One is knowledge of other traffic, in which they already know of the presence of other traffic on their approach or by using their senses while waiting, such as hearing and peripheral vision, to check that there will be no conflict with drivers. The other is that they know that other traffic should yield and wish to communicate their own intentions without showing insecurity.
A road user is assumed to want to be in their comfort zone at all times. This allows planning ahead and provides the largest experienced safety margins. To remain there, one must plan ahead - knowing where to go, where to be at what time, assessing and predicting others' movements, etc. The more easily the necessary information can be found in the environment, and the more certain the information is perceived to be (high predictability), the easier it is to have a rather accurate picture over a longer time horizon. Car trajectories are generally easier to predict, as their degrees of freedom are fewer. However, they typically move faster than cyclists, which can often mean that the car driver is more of an "actor", while the cyclist can either react, or cannot do much about the situation (especially when being overtaken). Also, misjudging the future actions of car drivers can have severe consequences.

Consequently, for cyclists to remain in their comfort zone, they either have to get out of the way of cars altogether (to avoid being on the receiving end of actions without being able to do anything about them), or to feel so sure about car drivers' actions that they still feel that they are in their comfort zone, or they trade in the feeling of comfort for efficiency or rule obedience. In situations where cyclists have more power to influence the situation (mostly at intersections), they can choose to act defensively or offensively, and they can communicate etc., which gives them more possibilities to manage their position within their comfort zone.

Although individual adaptations by our participants are studied here, it is important to acknowledge that adaptations to other people, such as road users, are interactions between the parties involved, and that it is not only one individual adapting to the other. For instance, this can be noted at the signalised intersection, where cyclists going straight on and car drivers turning right adapted to each other, with the situational demands including the presence, intention and relative speed of the other, expected time until the red light, and the restrictions imposed by the regulations.

Because the study was conducted in real traffic, no manipulation of the traffic lights was undertaken. There was a bias concerning driving and turning right at the signalised intersection (see Fig. 6), in that out of the eight participants who experienced a green traffic signal on approach, only one was a character driver and the rest were character cyclists. This may have affected the results, although it is not likely since all but one participant in total looked for vulnerable road users from behind before turning right. Even though the sample size was quite small, all 23 participants both drove a car and cycled through the five intersections. Hence, a lot of data was collected for each individual, allowing for withinsubject analyses. 
It is possible that more extreme grouping criteria, such as participants who never cycle but drive a long way every day versus participants who never drive but cycle several kilometres each day, would result in other outcomes. However, apart from the ethical problems of using people who are new to driving or riding in traffic, there could also be validity issues. Asking people to cycle or drive in a study when they never do so in their daily lives would produce behaviour that cannot be generalised to realistically occurring situations.

Summing up, in this study we could not demonstrate any differences in adaptive behaviour between character road-user roles, i.e. people who are more familiar with the car-driver role and those who are more familiar with the cyclist role in traffic. This conforms with previous simulator research on drivers' visual search behaviour, revealing no difference in drivers' visual attention to cyclists, depending on their own cycling experience [31]. Our findings suggest that the current situational demands are more important for adaptation than previous experience of a certain road-user role. If the demands are high, then the boundaries of the comfort zone are violated, and people adapt by trying to increase their information intake. Building the road infrastructure so that it is easy to interpret in general would be beneficial for both cyclists and drivers. In addition, clear and logical rules for all road users would minimise insecurity and facilitate staying in their comfort zone.

\section{Conclusions}

Experiences gained as a character driver or character cyclist were not found to be used in the other role. The current situation and the demands present at the time are influenced by the current road-user role and characterise the need to adapt. What trade-offs are made in order to return to the comfort zone depend on the specific situation, but also on the individual and his or her strategic decisions. It is recommended to build the road infrastructure so that it is easy to interpret and logical for all road users. Then there is a potential that road users will remain in their comfort zones to a larger extent and that fewer conflicts, and possibly accidents, due to false expectations will occur.

\section{Acknowledgements}

The authors wish to thank all those experiment leaders and researchers involved in the data collection and data reduction process.

\section{Authors' contributions}

SN analysed and interpreted the data, helped with data collection and authored the major part of the article. KK took part in the data collection and data reduction process and added part of the discussion section. KK and BJEJ both contributed to the article by continuous feed-back and discussion and BJEJ especially helped on the ECOM part of the paper. All authors read and approved the final manuscript.

\section{Funding}

The study was supported by the Strategic Vehicle Research and Innovation Programme (FFI), which is a partnership programme run jointly by the Swedish state and the Swedish automotive industry. The funding body had no role in the design of the study, data collection, analysis, interpretation of data or writing of the manuscript.

\section{Availability of data and materials}

The datasets used and analysed during the current study are available from the corresponding author on reasonable request.

\section{Competing interests}

The authors declare that they have no competing interests.

Received: 19 September 2019 Accepted: 20 January 2020

Published online: 02 March 2020

\section{References}

1. Assum, T., Bjørnskau, T., Fosser, S., \& Sagberg, F. (1999). Risk compensation-The case of road lighting. Accident Analysis \& Prevention, 31(5), 545-553.

2. Kallberg, V.-P. (1993). Reflector posts--signs of danger? Transportation research record, 1403, 57-66.

3. Hollnagel, E. (2016). Extended Control Model (ECOM). Retrieved from http:// erikhollnagel.com/ideas/ecom.html

4. Hollnagel, E., \& Woods, D. D. (2005). Joint cognitive systems: Foundations of cognitive systems engineering: $C R C$ press.

5. Gibson, J. J., \& Crooks, L. E. (1938). A theoretical field-analysis of automobiledriving. The American journal of psychology, 51(3), 453-471.

6. Engstrom, J., \& Ljung Aust, M. (2011). Adaptive behavior in the simulator: Implications for active safety system evaluation. In D. L. Fisher, M. Rizzo, J. Caird, \& J. D. Lee (Eds.), Handbook of driving simulation for engineering, medicine, and psychology. Boca Raton: CRC Press.

7. Ljung Aust, M., \& Engström, J. (2011). A conceptual framework for requirement specification and evaluation of active safety functions. Theoretical Issues in Ergonomics Science, 12(1), 44-65.

8. Panero, G. (2018). Drivers' comfort zone boundaries when overtaking pedestrians: Analysis of naturalistic driving and field test data. Sweden: Politecnico di Torino, Italy \& Chalmers University of technology Master's thesis 2018:66.

9. Bärgman, J., Smith, K., \& Werneke, J. (2015). Quantifying drivers' comfortzone and dread-zone boundaries in left turn across path/opposite direction (LTAP/OD) scenarios. Transportation Research Part F: Traffic Psychology and Behaviour, 35, 170-184

10. Summala, H. (2007). Towards understanding motivational and emotional factors in driver behaviour: Comfort through satisficing. In Modelling driver behaviour in automotive environments (pp. 189-207). Springer, London.

11. Adell, E., Nilsson, A., \& Kircher, K. (2014). Cyclists' use of mobile IT in Sweden-Usage and self-reported behavioural compensation. Paper presented at the International cycling safety conference, Gothenburg.

12. Fitch, G., Grove, K., Hanowski, R., \& Perez, M. (2014). Compensatory behavior of drivers when conversing on a cell phone: Investigation with naturalistic driving data. Transportation Research Record: Journal of the Transportation Research Board, 2434, 1-8.

13. Son, J., Lee, Y., \& Kim, M.-H. (2011). Impact of traffic environment and cognitive workload on older drivers' behavior in simulated driving. International Journal of Precision Engineering and Manufacturing, 12(1), 135-141.

14. de Raedt, R., \& Ponjaert-Kristoffersen, I. (2000). Cognitive/neuropsychological functioning and compensation related to car driving performance in older adults. Berne: Paper presented at the ICTTP 2000.

15. te Velde, A. F., van der Kamp, J., Barela, J. A., \& Savelsbergh, G. J. (2005). Visual timing and adaptive behavior in a road-crossing simulation study. Accident Analysis \& Prevention, 37(3), 399-406.

16. Rudin-Brown, C., \& Jamson, S. (2013). Behavioural adaptation and road safety: Theory, evidence and action: CRC press.

17. Blanchard, R. A., \& Myers, A. M. (2010). Examination of driving comfort and self-regulatory practices in older adults using in-vehicle devices to assess natural driving patterns. Accident Analysis \& Prevention, 42(4), 1213-1219.

18. Charlton, J. L., Oxley, J., Fildes, B., Oxley, P., Newstead, S., Koppel, S., \& O'Hare, M. (2006). Characteristics of older drivers who adopt self-regulatory driving 
behaviours. Transportation Research Part F: Traffic Psychology and Behaviour, 9(5), 363-373.

19. Füssl, E., \& Haupt, J. (2017). Understanding cyclist identity and related interaction strategies. A novel approach to traffic research. Transportation Research Part F: Traffic Psychology and Behaviour, 46, 329-341.

20. Hoekstra, A., Twisk, D., \& Hagenzieker, M. (2018). Do road user roles serve as social identities? Differences between self-described cyclists and car drivers. Transportation Research Part F: Traffic Psychology and Behaviour, 59, 365-377.

21. Räsänen, M., \& Summala, H. (1998). Attention and expectation problems in bicycle-car collisions: An in-depth study. Accident Analysis \& Prevention, 30(5), 657-666.

22. Miranda-Moreno, L. F., Strauss, J., \& Morency, P. (2011). Disaggregate exposure measures and injury frequency models of cyclist safety at signalized intersections. Transportation research record, 2236(1), 74-82.

23. Goddard, T., Dill, J., \& Monsere, C. M. (2016). Driver attitudes about bicyclists: Negative evaluations of rule-following and predictability. Washington DC: Paper presented at the Transportation Research Board 95th annual meeting.

24. O'Connor, J. P., \& Brown, T. D. (2010). Riding with the sharks: Serious leisure cyclist's perceptions of sharing the road with motorists. Journal of Science and Medicine in Sport, 13(1), 53-58.

25. Sanders, R. L. (2015). Perceived traffic risk for cyclists: The impact of near miss and collision experiences. Accident Analysis \& Prevention, 75, 26-34.

26. Kircher, K., Fors, C., \& Ahlstrom, C. (2014). Continuous versus intermittent presentation of visual eco-driving advice. Transportation Research Part F: Traffic Psychology and Behaviour, 24, 27-38.

27. Birrell, S. A., \& Fowkes, M. (2014). Glance behaviours when using an invehicle smart driving aid: A real-world, on-road driving study. Transportation Research Part F: Traffic Psychology and Behaviour, 22, 113-125.

28. Kircher, K., Eriksson, O., Forsman, Å., Vadeby, A., \& Ahlstrom, C. (2017). Design and analysis of semi-controlled studies. Transportation Research Part F: Traffic Psychology and Behaviour, 46, 404-412.

29. SFS 2007:101. Förordning om ändring i trafikförordningen (1998:1276). Stockholm: Näringsdepartementet.

30. Nygårdhs, S., Ahlström, C., Ihlström, J., \& Kircher, K. (2018). Bicyclists' adaptation strategies when interacting with text messages in urban environments. Cognition, Technology \& Work, 20(3), 377-388.

31. Robbins, C. J., \& Chapman, P. (2018). Drivers' visual search behavior toward vulnerable road users at junctions as a function of cycling experience. Human Factors, 60(7), 889-901.

\section{Publisher's Note}

Springer Nature remains neutral with regard to jurisdictional claims in published maps and institutional affiliations.

\section{Submit your manuscript to a SpringerOpen ${ }^{\circ}$ journal and benefit from:}

- Convenient online submission

- Rigorous peer review

- Open access: articles freely available online

- High visibility within the field

- Retaining the copyright to your article

Submit your next manuscript at $\boldsymbol{\nabla}$ springeropen.com 